\title{
Worker Protection Standard: Requirements for Commercial Pesticide Handler Employers'
}

\author{
Frederick M. Fishel ${ }^{2}$
}

\section{Background}

In 1992, the US Environmental Protection Agency (EPA) issued a comprehensive regulation called the Worker Protection Standard for Agricultural Pesticides (WPS). This regulation is primarily intended to reduce the risks of illness or injury to workers and handlers resulting from occupational exposures to pesticides used in the production of agricultural plants on agricultural establishments (i.e., farms, forests, nurseries, and enclosed space production facilities, such as greenhouses). The WPS requires agricultural employers to take steps to reduce pesticide-related risks when agricultural workers and pesticide handlers are exposed to these pesticides. The EPA has made several changes to the WPS since it was fully implemented in 1995. On November 2, 2015, the EPA revised the WPS, making significant changes to the rule's requirements. Most of the revised provisions became effective January 2, 2017; there are four provisions that were delayed until January 2, 2018. In late 2016, the EPA released the revised How to Comply manual to provide an updated resource. The entire document is posted on their website at https://www.epa.gov/ sites/production/files/2016-09/documents/htcmanual_final. pdf. This document will address the WPS protections commercial pesticide handler employers must provide to their handlers. Commercial pesticide handling establishments and their employees are included in WPS when they apply WPS-labeled pesticide products on agricultural establishments, even if some of the pesticide handling tasks (mixing, loading, disposal, etc.) take place somewhere other than the agricultural establishment that is the treatment site. Owners and managers of commercial pesticide handling establishments have WPS responsibilities as commercial pesticide handler employers.

\section{How is a commercial pesticide handler establishment defined under the WPS?}

It is defined as an enterprise other than an agricultural establishment that provides pesticide handler or crop advising services to agricultural establishments. In other words, this is usually a custom pesticide application business that is hired by a farm, forest, nursery, or enclosed space agricultural production facility to apply pesticides or to provide crop-consulting services.

\section{How is a commercial pesticide handler employer (CPHE) defined under the WPS?}

This is any person, other than an agricultural employer, who employs any handler to perform handler activities on an agricultural establishment.

\footnotetext{
1. This document is PI275, one of a series of the Agronomy Department, UF/IFAS Extension. Original publication date January 2018. Visit the EDIS website at http://edis.ifas.ufl.edu.
}

2. Frederick M. Fishel, professor, Agronomy Department, UF/IFAS Extension, Gainesville, FL 32611.

The Institute of Food and Agricultural Sciences (IFAS) is an Equal Opportunity Institution authorized to provide research, educational information and other services only to individuals and institutions that function with non-discrimination with respect to race, creed, color, religion, age, disability, sex, sexual orientation, marital status, national origin, political opinions or affiliations. For more information on obtaining other UF/IFAS Extension publications, contact your county's UF/IFAS Extension office. 


\section{What are the responsibilities of the CPHE?}

The CPHE must ensure:

- All pesticides are used consistent with the pesticide product label at all times, including following the WPS requirements when applicable.

- Each worker and handler receives the protections required by the WPS.

- Each handler or worker that conducts early-entry tasks is at least 18 years of age.

- Employees do not clean, repair, or adjust pesticide application equipment without completing WPS handler training.

- Other persons (not employed by the agricultural establishment) do not clean, repair, or adjust pesticide application equipment until they are told:

- That the equipment may be contaminated with pesticides.

- About the potentially harmful effects of pesticide exposure.

- How they are to handle the equipment to limit exposure to pesticides.

- How to wash themselves and/or their clothes to prevent or remove pesticide residues.

- Handlers are given instruction in the safe operation of equipment used to mix, load, transfer, or apply pesticides.

- Before any equipment is used to mix, load, transfer, or apply pesticides, it must be inspected for leaks, clogged nozzles, and worn or damaged parts. Any faulty equipment must be repaired or replaced before use.

- Handlers that apply pesticides on an agricultural establishment are informed about, or are aware of, the location and description of any treated areas on the agricultural establishment where a restricted-entry interval (REI) is in effect, and the restrictions on entering those areas.

- Records or other information required by WPS are provided for inspection to an employee of EPA or any duly authorized representative of the federal, state, or tribal agency responsible for pesticide enforcement.

\section{What are the responsibilities of employers to instruct supervisors of handlers?}

If a CPHE employs anyone to supervise handlers, or hires handlers through a labor contractor, the CPHE must provide sufficient instructions to the supervisors and/or labor contractors to ensure that handlers receive all required WPS protections. The instructions must specify which tasks the labor contractor and/or supervisors are responsible for in order to comply with the WPS. The CPHE must also require labor contractors and anyone who supervises handlers to provide sufficient information and directions to each handler to ensure that they can comply with the WPS provisions applicable to their duties and tasks as a handler. The CPHE and their supervisors must clearly understand each of the responsibilities for complying with the WPS and ensure that they are implemented. Even if the CPHE assigns a supervising employee or labor contractor to carry out the duties required by the WPS, the CPHE is ultimately responsible for making sure those duties are performed.

\section{The WPS requires that agricultural establishment employers provide emergency assistance to their workers and handlers for pesticide exposure incidents. Does this also pertain to the CPHE?}

Yes. If there is reason to believe that a handler employed by a CPHE has experienced a potential pesticide exposure during or within 72 hours after his or her employment, and needs emergency medical treatment, the CPHE must do all of the following promptly after learning of the possible poisoning or injury:

- Provide emergency transportation. Promptly make emergency transportation available to take the handler from the commercial pesticide handling establishment, or any agricultural establishment on which the handler may be working on behalf of the CPHE, to a medical care facility capable of providing emergency medical treatment to a person exposed to pesticides. There are several options in how this may be done: taking the employee to the medical care facility, calling an emergency vehicle (such as an ambulance), or making sure the employee has a ride to the medical care facility with someone else. 
- Provide emergency information. The CPHE must provide all of the following information to the treating medical personnel:

- Copies of the applicable safety data sheet(s) and the product name(s), EPA registration number(s), and active ingredient(s) for each pesticide product to which the person may have been exposed.

- The circumstances of application or use of the pesticide on the agricultural establishment.

- The circumstances that could have resulted in exposure to the pesticide.

\section{Agricultural establishment} employers are required to provide training for their handler employees. Does this apply for

\section{CPHEs?}

Yes, it does apply for CPHEs. The full details of handler training may be viewed in EDIS document PI268, Worker Protection Standard: Training Workers and Handlers under the 2016 Revision Requirements, at https://edis.ifas.ufl.edu/ pi268.

When CPHEs are hired to make pesticide applications at agricultural establishments, are they required to provide pesticide application information to the establishment owner/employer?

Yes. It is best if, prior to the application, the CPHE and agricultural employer agree upon a way to communicate any changes that may occur regarding the pesticide application to ensure receipt of the information. This information exchange can be accomplished through electronic media, telephone, or other means.

The purpose of this exchange of information is to allow the agricultural employer the opportunity to inform workers or handlers of pesticide applications made, restricted areas, and to record and display the appropriate information.
What specific information is the CPHE required to provide to the agricultural establishment employer?

The CPHE must inform the agricultural employer of the following:

- The specific location and description of the area(s) on the agricultural establishment that are to be treated with a pesticide product,

- Date, start time, and estimated end time of the pesticide application,

- Pesticide product name(s),

- The product(s) EPA registration number(s), and active ingredient(s),

- REI for the pesticide product(s),

- Whether the pesticide product(s) labeling requires posting, oral notification, or both to be conducted by the agricultural employer, and

- Any other specific requirements on the pesticide product labeling concerning protection of workers and other persons during or after application.

\section{Isn't the agricultural employer also obligated to provide pesticide application information to the CPHE in the event there are treated areas present?}

Yes. In addition, the agricultural employer must provide certain information to the CPHE about treated areas on the agricultural establishment. The purpose of this exchange of information (and the requirement for the CHPE to pass it along to the handler) is to ensure that a commercial pesticide handler is aware of areas under REIs on an agricultural establishment close to where he/she will be working.

\section{What specific information is the agricultural establishment employer required to provide to the CPHE?}

Before a commercial pesticide handler enters an agricultural establishment, the agricultural employer must inform the CPHE about treated areas and any restrictions 
on the establishment, and the CPHE must provide that information to the commercial pesticide handler. While it is the agricultural employer's responsibility to inform the CPHE, the CPHE must obtain this information so it can be communicated to their handler employees. The agricultural employer must provide to the CPHE:

- The specific location and description of any treated areas on the agricultural establishment under a restricted-entry interval that the commercial pesticide handler may be in (or walk within $1 / 4$ mile of), and

- Any restrictions on entering those areas. The CPHE must inform their handler of the information provided by the agricultural employer.

\section{Changing conditions are}

\section{a constant in agricultural} production; so, what if the pesticide information were to

\section{change?}

The CPHE must provide the agricultural employer with updated information prior to the application when there are any changes to:

- The location to be treated,

- REI,

- Method of notification,

- Labeling requirements to protect workers/other persons, or

- The start time which will cause it to be earlier than estimated.

If the product information changes or there are other changes to the date or start and end time, the CPHE must provide the updated information to the agricultural employer within 2 hours after completing the application.

\section{Is the CPHE required to provide decontamination supplies to pesticide handlers they employ?}

Yes. The full details regarding decontamination supplies may be viewed in EDIS document PI261, A Summary of Revisions to the Worker Protection Standard - 2015, at http://edis.ifas.ufl.edu/pi261.

\section{Are CPHEs allowed to retaliate against employees who attempt to comply with the provisions of the WPS?}

Retaliation is a serious violation of federal law. The commercial pesticide handler employer, their supervisors, or others cannot intimidate, threaten, coerce, discriminate against, prevent, discourage, or fire any handler for complying or attempting to comply with the WPS. Additionally, the commercial pesticide handler employer cannot retaliate in any manner if:

- Any handler refuses to participate in any activity that the handler reasonably believes to be in violation of the WPS,

- Any handler has (or is about to) report WPS noncompliance to appropriate authorities for enforcement of WPS provisions, or

- Any handler agrees to provide information to the EPA or any duly authorized representative of a federal, state, or tribal government about WPS compliance, or assists or participates in any manner in an investigation, proceeding, or hearing concerning WPS compliance.

\section{Could the CPHE face penalties for noncompliance with the WPS?}

CPHEs can be subject to civil and criminal penalties if they do not comply with the federal WPS, including all revisions to this rule. Failure to comply is a pesticide misuse violation, because the WPS is referenced on applicable pesticide product labeling. Failure to comply with distinct requirements of the WPS can result in independently assessable charges, even if the violative acts occurred during one pesticide application.

The Federal Insecticide, Fungicide and Rodenticide Act (FIFRA) includes provisions that hold CPHEs liable for a WPS penalty if another person employed by or acting for them, including supervisors, fails to comply with any WPS requirements. The term "acting for" includes both employment and contractual relationships. 


\section{Should a violation occur, what are}

the penalties and fines assessed to the CPHE?

Currently, a federal civil penalty of up to $\$ 18,750$ per violation against commercial applicators (owners/operators of pesticide handler establishments) and other persons may be levied.

\section{Additional Information}

Frederick M. Fishel. 2015. A Summary of Revisions to the Worker Protection Standard - 2015. PI261. Gainesville: University of Florida Institute of Food and Agricultural Sciences. http://edis.ifas.ufl.edu/pi261

Frederick M Fishel. 2016. Worker Protection Standard: Training Workers and Handlers under the 2016 Revision Requirements. PI268. Gainesville: University of Florida Institute of Food and Agricultural Sciences. https://edis.ifas. ufl.edu/pi268

US EPA. 2016. "How to Comply with the 2015 Revised Worker Protection Standard for Agricultural Pesticides: What Owners and Employers Need to Know." EPA 735-B16-001. United States Environmental Protection Agency. https://www.epa.gov/sites/production/files/2016-09/documents/htcmanual_final.pdf 